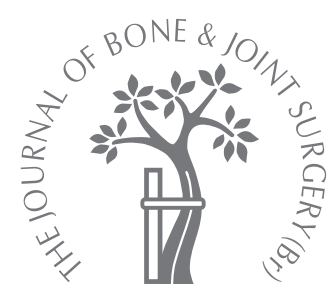

S. A. Hanna, M. D. Sewell, W. J. S. Aston, R. C. Pollock, J. A. Skinner, S. R. Cannon, T. W. R. Briggs

From The Sarcoma Unit, Royal National Orthopaedic Hospital, Stanmore, England

\footnotetext{
S. A. Hanna, MRCS, Specialist Registrar in Trauma and Orthopaedics M. D. Sewell, MRCS Specialist Registrar in Trauma and Orthopaedics

W. J. S. Aston, FRCS(Orth) Consultant Orthopaedic Surgeon

R. C. Pollock, FRCS(Orth), Consultant Orthopaedic Surgeon

J. A. Skinner, FRCS(Orth), Consultant Orthopaedic Surgeon

S. R. Cannon, MA MCh(Orth), FRCS, Consultant Orthopaedic Surgeon T. W. R. Briggs, MD(Res), $\mathrm{MCh}$ (Orth), FRCS, Professor of Orthopaedic Surgery The Sarcoma Unit Royal National Orthopaedic Hospital, Brockley Hill,

Stanmore, Middlesex HA7 4 LP, UK.

Correspondence should be sent to Mr S. A. Hanna; e-mail: sammyhanna@hotmail.com
}

(c)2010 British Editorial Society of Bone and Joint Surgery doi:10.1302/0301-620X.92B6. $23449 \$ 2.00$

$J$ Bone Joint Surg $[\mathrm{Br}]$ 2010;92-B:867-74. Received 18 September 2009; Accepted after revision 29 January 2010

\title{
Femoral diaphyseal endoprosthetic reconstruction after segmental resection of primary bone tumours
}

\begin{abstract}
Segmental resection of malignant bone disease in the femoral diaphysis with subsequent limb reconstruction is a major undertaking. This is a retrospective review of 23 patients who had undergone limb salvage by endoprosthetic replacement of the femoral diaphysis for a primary bone tumour between 1989 and 2005.

There were 16 males and seven females, with a mean age of 41.3 years (10 to 68 ). The mean overall follow-up was for 97 months (3 to 240), and 120 months (42 to 240) for the living patients. The cumulative patient survival was $77 \%(95 \%$ confidence interval $63 \%$ to $\mathbf{9 5 \% )}$ at ten years. Survival of the implant, with failure of the endoprosthesis as an endpoint, was $85 \%$ at five years and $68 \%(95 \%$ confidence interval $42 \%$ to $92 \%)$ at ten years. The revision rate was $22 \%$ and the overall rate of re-operation was $26 \%$. Complications included deep infection $(4 \%)$, breakage of the prosthesis $(8 \%)$, periprosthetic fracture $(4 \%)$, aseptic loosening $(4 \%)$, local recurrence $(4 \%)$ and metastases $(17 \%)$. The 16 patients who retained their diaphyseal endoprosthesis had a mean Musculoskeletal Tumour Society score of $\mathbf{8 7 \%}$ $(67 \%$ to $93 \%)$. They were all able to comfortably perform most activities of daily living.

Femoral diaphyseal endoprosthetic replacement is a viable option for reconstruction following segmental resection of malignant bone disease. It allows immediate weightbearing, is associated with a good long-term functional outcome, has an acceptable complication and revision rate and, most importantly, does not appear to compromise patient survival.
\end{abstract}

The femur is the long bone most commonly affected by primary and secondary malignant disease. ${ }^{1}$ Primary bone sarcomas usually occur in the proximal and distal ends of the bone; lesions confined to the diaphysis are unusual. ${ }^{1,2}$

Limb salvage in cases of diaphyseal tumours, although favoured by patients, represents a challenging reconstructive problem, because of the significant bony defects resulting from en bloc excision of the tumour. Segmental resection allows preservation of the hip and knee joints as well as the physes in children, making it an attractive option with clear functional benefits.

The surgical options for reconstruction of a femoral diaphyseal defect remain limited, technically challenging, and have a variable and unpredictable outcome. Available methods include the use of autogenous vascularised fibular grafts, ${ }^{3-5}$ autogenous extracorporeally irradiated bone, ${ }^{6-9}$ massive allografts, ${ }^{10-16}$ a combination of autogenous fibular grafts and allografts, ${ }^{17,18}$ segmental bone transportation, ${ }^{19,20}$ and intercalary custom-made endoprostheses. ${ }^{21-23}$ The aim of this study was to evaluate the functional and oncological results associated with custom-made intercalary femoral diaphyseal endoprosthetic reconstruction after primary excision of bone tumours.

Patients and Methods

We identified 25 consecutive patients who, between 1989 and 2005, had undergone femoral diaphyseal reconstruction with a custommade endoprosthesis following excision of a primary bone tumour. Two were lost to followup; the remaining 23 were reviewed retrospectively. We obtained data from the case notes, the hospital databases, imaging studies and outpatient clinic reviews.

There were 16 males and seven females with a mean age of 41.3 years ( 10 to 68 ) at the time of operation. Five patients died of their disease. The remaining 18 were available for functional assessment.

All the patients were referred to our supraregional regional bone and soft-tissue sarcoma service with a primary bone sarcoma arising in the femoral diaphysis and were managed in a 
Table I. Details of the 23 patients included in the study

\begin{tabular}{|c|c|c|c|c|c|c|c|c|c|c|}
\hline Case & $\begin{array}{l}\text { Age } \\
\text { (yrs) }\end{array}$ & Gender & Diagnosis & $\begin{array}{l}\text { Follow-up } \\
\text { (yrs) }\end{array}$ & $\begin{array}{l}\text { Patient survival } \\
\text { (mths) }\end{array}$ & $\begin{array}{l}\text { Implant survival } \\
\text { (mths) }\end{array}$ & $\begin{array}{l}\text { Post-operative } \\
\text { complications }\end{array}$ & Radiotherapy & Chemotherapy & $\begin{array}{l}\text { MSTS }^{*} \\
(\%)^{*}\end{array}$ \\
\hline 1 & 29 & $\mathrm{~F}$ & Chondrosarcoma & 20 & Living at 240 & 240 & & $\mathrm{~N}$ & $\mathrm{~N}$ & 93 \\
\hline 2 & 17 & $M$ & Osteosarcoma & 2.4 & Died at 29 & 29 & Metastases & & & $\mathrm{N} / \mathrm{A}$ \\
\hline 3 & 55 & $\mathrm{M}$ & Chondrosarcoma & 17 & Living at 204 & 204 & & $\mathrm{~N}$ & $\mathrm{~N}$ & 93 \\
\hline 4 & 72 & $\mathrm{~F}$ & Osteosarcoma & 1.3 & Died at 16 & 16 & $\begin{array}{l}\text { Local recurrence of metas- } \\
\text { tases }\end{array}$ & & & $\mathrm{N} / \mathrm{A}$ \\
\hline \multirow[t]{2}{*}{5} & 18 & $\mathrm{M}$ & Osteosarcoma & 14.6 & Living at 175 & 106 & $\begin{array}{l}\text { Chest metastases at } \\
84 \text { months - excision }\end{array}$ & $\mathrm{N}$ & $\mathrm{Y}$ & 87 \\
\hline & & & & & & & $\begin{array}{l}\text { Fracture of prosthesis at } \\
106 \text { months - revision }\end{array}$ & & & \\
\hline 6 & 54 & $\mathrm{~F}$ & Osteosarcoma & 0.3 & Died at 4 & 4 & Metastases & $\mathrm{N}$ & $\mathrm{Y}$ & $N / A$ \\
\hline 7 & 59 & $\mathrm{M}$ & Osteosarcoma & 14 & Living at 168 & 168 & & $\mathrm{~N}$ & $\mathrm{Y}$ & 87 \\
\hline 8 & 47 & $M$ & Chondrosarcoma & 12 & Living at 144 & 144 & & $\mathrm{~N}$ & $\mathrm{~N}$ & 87 \\
\hline 9 & 25 & $\mathrm{M}$ & Ewing's sarcoma & 12.9 & Living at 155 & 155 & & $\mathrm{Y}$ & $\mathrm{Y}$ & 93 \\
\hline 10 & 68 & $\mathrm{~F}$ & Chondrosarcoma & 11 & Living at 133 & 89 & $\begin{array}{l}\text { Aseptic loosening } \\
\text { with distal bone loss at } 89 \\
\text { months - revision to } \\
\text { a distal femoral } \\
\text { replacement }\end{array}$ & $N$ & $\mathrm{~N}$ & 67 \\
\hline 11 & 61 & $M$ & Chondrosarcoma & 11.7 & Living at 140 & 140 & & $\mathrm{~N}$ & $\mathrm{~N}$ & 93 \\
\hline 12 & 68 & $M$ & Chondrosarcoma & 9.7 & Living at 117 & 117 & & $\mathrm{~N}$ & $\mathrm{~N}$ & 87 \\
\hline 13 & 50 & $\mathrm{M}$ & Chondrosarcoma & 10 & Living at 120 & 3 & $\begin{array}{l}\text { Periprosthetic } \\
\text { fracture (proximal) at } \\
3 \text { months - revision of } \\
\text { proximal component }\end{array}$ & $\mathrm{N}$ & $\mathrm{N}$ & 80 \\
\hline 14 & 49 & $\mathrm{M}$ & $\begin{array}{l}\text { Malignant fibrous } \\
\text { histiocytoma }\end{array}$ & 0.3 & Died at 3 & 3 & Metastases & $\mathrm{Y}$ & $\mathrm{Y}$ & $\mathrm{N} / \mathrm{A}$ \\
\hline \multirow[t]{2}{*}{15} & 66 & $\mathrm{~F}$ & $\begin{array}{l}\text { Malignant fibrous } \\
\text { histiocytoma }\end{array}$ & 8.2 & Living at 98 & 33 & $\begin{array}{l}\text { Fracture of prosthesis } \\
\text { at } 33 \text { months - revision }\end{array}$ & $\mathrm{Y}$ & $\mathrm{N}$ & 67 \\
\hline & & & & & & & $\begin{array}{l}\text { Metastases at } 36 \\
\text { months - chemotherapy }\end{array}$ & & & \\
\hline 16 & 12 & $M$ & Ewing's sarcoma & 8 & Living at 96 & 96 & & $\mathrm{~N}$ & $\mathrm{Y}$ & 93 \\
\hline 17 & 22 & $\mathrm{M}$ & Osteosarcoma & 7.4 & Living at 89 & 89 & & $\mathrm{~N}$ & $\mathrm{Y}$ & 87 \\
\hline 18 & 64 & $\mathrm{M}$ & $\begin{array}{l}\text { Malignant fibrous } \\
\text { histocytoma }\end{array}$ & 6.2 & Living at 75 & 75 & $\begin{array}{l}\text { Chest metastases at } \\
24 \text { months - excision }\end{array}$ & $\mathrm{Y}$ & $\mathrm{Y}$ & 67 \\
\hline 19 & 10 & $\mathrm{~F}$ & Ewing's sarcoma & 5.6 & Living at 67 & 12 & $\begin{array}{l}\text { Deep infection with bone } \\
\text { loss distally at } \\
12 \text { months - revision to } \\
\text { distal femoral } \\
\text { replacement }\end{array}$ & $\mathrm{N}$ & $\mathrm{Y}$ & 53 \\
\hline 20 & 24 & $\mathrm{~F}$ & Osteosarcoma & 0.8 & Died at 10 & 10 & Metastases & $\mathrm{N}$ & $\mathrm{Y}$ & $\mathrm{N} / \mathrm{A}$ \\
\hline 21 & 15 & $M$ & Osteosarcoma & 4.6 & Living at 55 & 55 & & $\mathrm{~N}$ & $\mathrm{Y}$ & 93 \\
\hline 22 & 14 & $\mathrm{M}$ & Osteosarcoma & 4.2 & Living at 50 & 50 & & $\mathrm{~N}$ & $\mathrm{Y}$ & 87 \\
\hline 23 & 52 & $M$ & Multiple myeloma & 3.5 & Living at 42 & 42 & & $\mathrm{~N}$ & $\mathrm{~N}$ & 93 \\
\hline
\end{tabular}

* MSTS, musculoskeletal tumor society score; N/A, not available

multidisciplinary setting. Pre-operative imaging for staging included plain radiographs, technetium $\left(\mathrm{TC}^{99}\right)$ bone scans, CT and MRI. Needle and/or open biopsies were obtained to confirm the diagnosis. Neoadjuvant/adjuvant chemoand radiotherapy were administered when recommended by oncologists according to nationally agreed protocols. Endoprosthetic replacement was not considered in the presence of extensive soft-tissue disease or invasion of the neurovascular bundle.

There were three cases of Ewing's sarcoma, seven of chondrosarcoma, nine of osteosarcoma, three of malignant fibrous histiocytoma and one of multiple myeloma (Table I). Functional outcome. The 18 patients living at the time of this review were assessed using the Musculoskeletal Tumour Society (MSTS) scoring system, which is used for the functional evaluation of reconstructive procedures after skeletal resection. For the lower limbs, this is based on six categories; pain, level of activity and restriction, emotional acceptance, use of orthopaedic supports, walking ability and gait, each with a maximum of five points for the best function. The MSTS is calculated as a percentage of the maximum possible score, hence a higher percentage indicates a better functional outcome.

Statistical analysis. Kaplan-Meier survival curves for both implant and patient were used to compare the rates of survival. Survival of the implant was analysed with failure of the endoprosthesis as an endpoint. The time to failure was defined as the time from the date of the original operation to the need for any revision to exchange the prosthesis or part of it (e.g. aseptic loosening, fracture, infection, breakages etc.). Patients were censored for statistical analysis, with the observation stopped before the event occurred if 

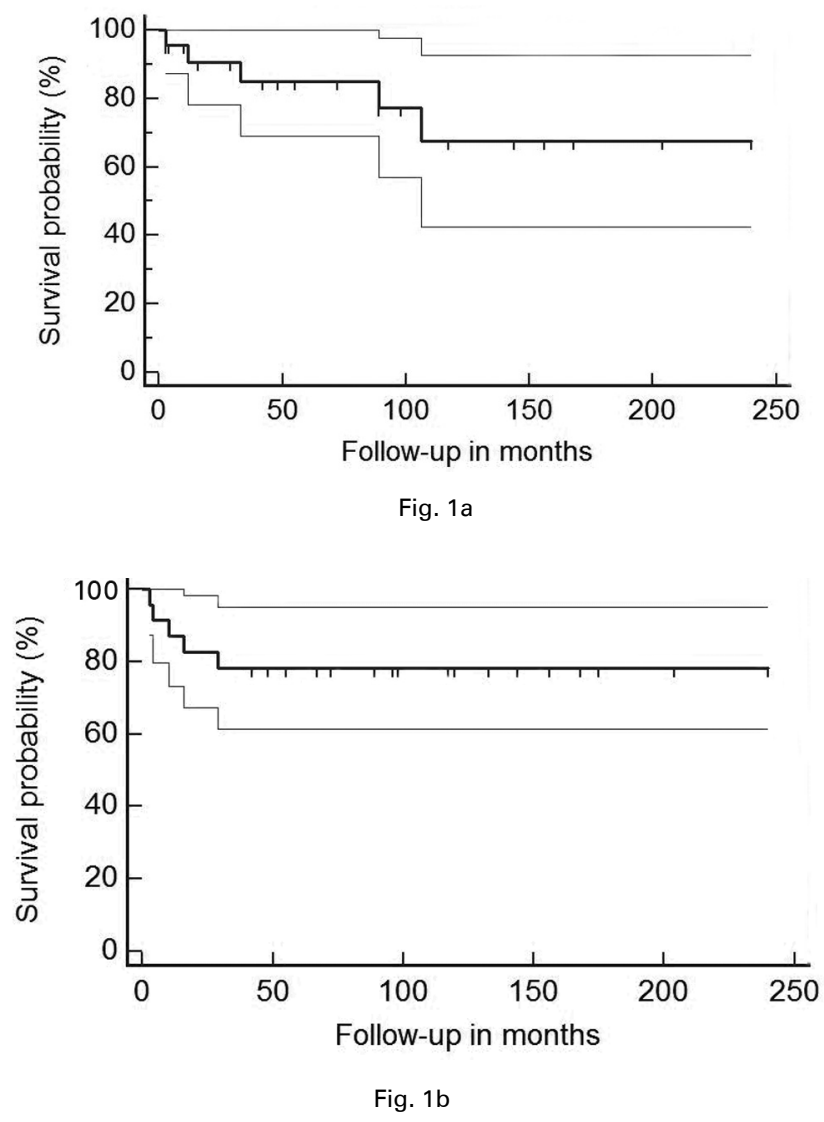

Kaplan-Meier survival curves for a) implant and b) patients.

failure had not occurred when the patient was last assessed (Fig. 1).

Fisher's exact test was used to evaluate the effect of categorical variables such as age, gender, chemotherapy and radiotherapy on the functional outcome. A two-tailed p-value of $\leq 0.05$ was considered to be statistically significant.

The prosthesis. The prosthesis is custom-made (Centre for Biomechanical Engineering of University College London in association with Stanmore Implants Worldwide Ltd, Stanmore, Middlesex) of titanium alloy (Ti $6 \mathrm{~A} 14 \mathrm{~V}$ ). It is manufactured using computer-aided design and computeraided manufacturing technologies after determining the levels for femoral transection on pre-operative plain radiographs and CT/MRI. The shaft is made of two parts, which are connected together at operation with two bolts (Fig. 2). Each end has an intramedullary stem which is cemented into the femoral canal. Both stems are fluted to provide rotational stability. In cases where completed excision of the tumour is expected to result in a limited length of intramedullary canal at either end necessitating the use of a shorter stem, fixation may be enhanced with the use of extracortical plates. In recent years, the design of the prosthesis has been modified to include hydroxyapatite (HA) collars at the bone-prosthesis junctions, with the potential for osseointegration. This results in reactive bone formation growing from the transection site over the shaft

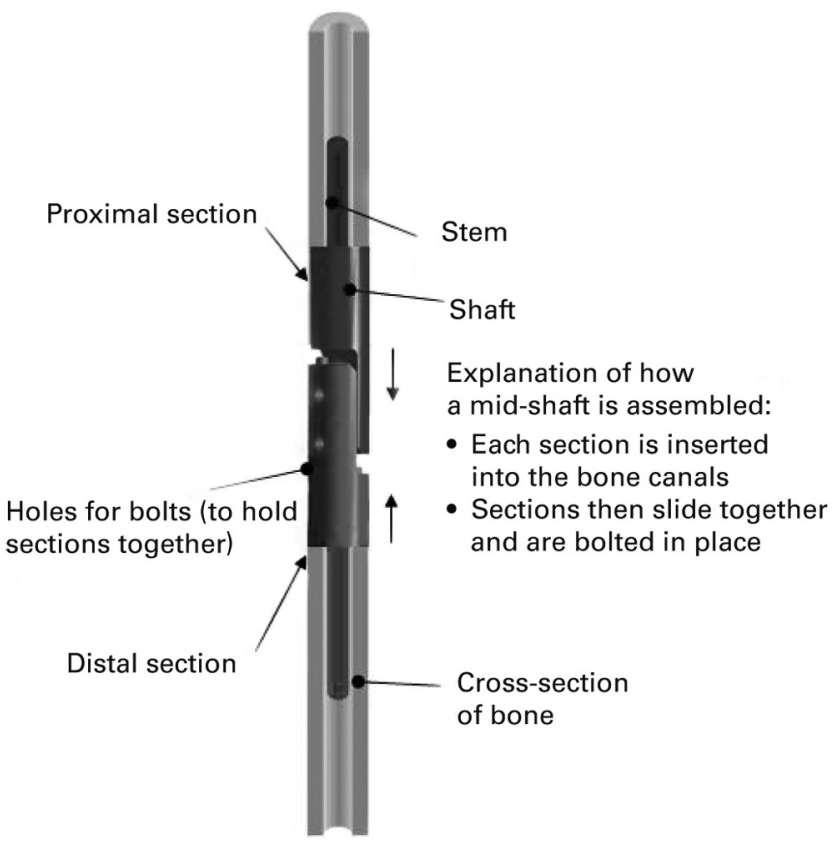

Fig. 2

Diagram of the femoral diaphyseal endoprosthesis.

of the implant to form a bony bridge. This is believed to reduce loosening by acting as a seal at the bone-implant interface, preventing the migration of wear particles. ${ }^{24}$

Surgical technique. The procedure is performed with the patient in the lateral position. An anterolateral longitudinal femoral incision is made, taking a lip of skin with the biopsy track. The fascia lata is split and vastus lateralis dissected out. The tumour is identified and the bony transection points, as identified on pre-operative imaging, are then accurately marked. Resection of the tumour is carried out according to the principles defined by Enneking et al, ${ }^{24}$ endeavouring to achieve en bloc excision with a surrounding cuff of normal tissue. Proximal and distal imprints are taken. Haemostasis is achieved and the proximal and distal ends of the femur are reamed to take the prosthesis. After washing with normal saline pulsatile lavage and drying, both stems are cemented in situ in the proximal and distal canals, with orientation and rotation carefuly adjusted. The prosthesis is then assembled and connected using two bolts (Fig. 2). After checking leg lengths and a further washout, the soft tissues and skin are closed in layers. Intravenous antibiotics are continued for three days after operation. Active physiotherapy and full weight-bearing are commenced on the first or second day after surgery, as pain permits. The patients are then followed up clinically and radiologically until the wound has healed, and then according to their primary diagnosis (Figs 3 to 7).

\section{Results}

The mean overall follow-up was for 97 months ( 3 to 240), and 120 months (36 to 240) for the patients still living. Five patients died of their disease at a mean of 12 months (3 to 29) 


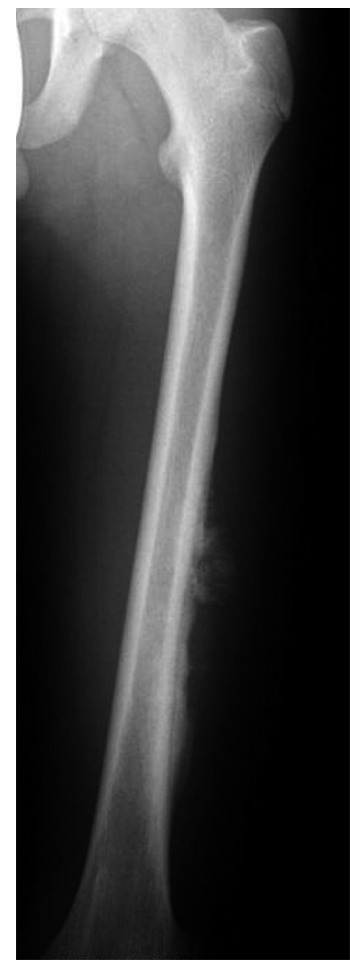

Fig. 3

Anteroposterior radiograph of a left femur showing a high-grade surface osteosarcoma. There is an extensive, partially ossified lesion arising from the lateral aspect of the distal diaphyseal cortex with an overlying soft-tissue mass.

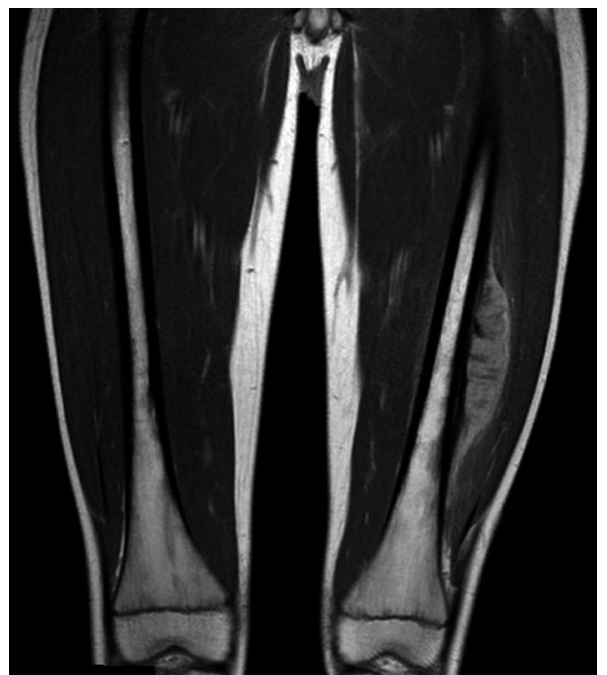

Fig. 4

Coronal T1-weighted MR scan showing the corresponding soft-tissue mass.

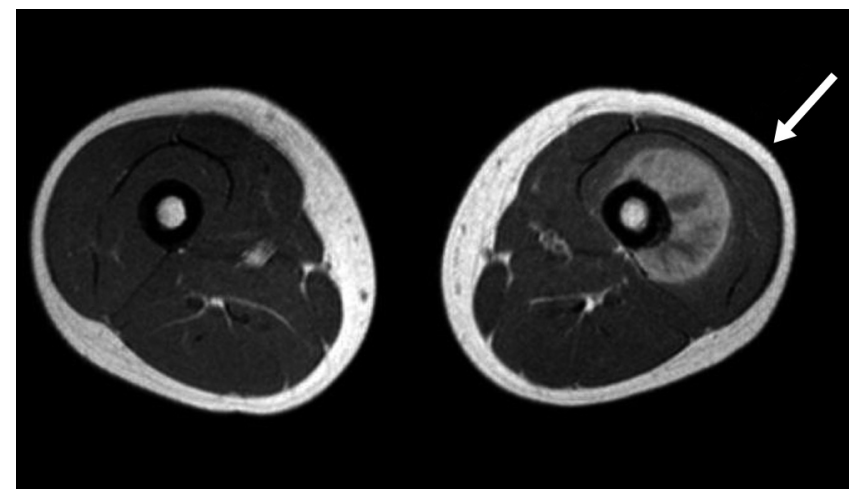

Fig. 5

post-operatively, four of whom had lung metastases at presentation. The cumulative patient survival was $77 \%(95 \%$ confidence interval (CI): $63 \%$ to $96 \%$ ) at ten years (Fig. 1). New metastases, all pulmonary, occurred in four patients post-operatively at a mean of 37 months (6 to 84). In two patients these were managed by surgical excision and in the other two by chemotherapy. There was one case of local recurrence in a high-grade osteosarcoma occurring in one of the deceased patients prior to death.

Survival of the prosthesis was $85 \%$ at five years and $68 \%$ (95\% CI: $42 \%$ to $92 \%$ ) at ten years. The rate of revision was $22 \%$ and the overall rate of re-operation was $26 \%$. There was one deep infection with coagulase-negative staphylococci associated with significant bone loss distally, which occurred 12 months after operation. The patient went on to have a two-stage revision to a distal femoral replacement, with the infection subsequently eradicated both clinically and biochemically.

In two patients the shaft of the endoprosthesis fractured following falls at 33 and 106 months. Both underwent revision by exchanging thewhole prosthesis. Their MSTS scores at review were $67 \%$ and $87 \%$, respectively. the proximal stem after a fall at three months. This was managed by a revision procedure during which the prosthesis was dismantled by removing the two connecting bolts. Only the proximal part was exchanged for a longer one, the distal part was found to be well fixed. The patient remains well 106 months after revision, with an MSTS score of $80 \%$.

Aseptic loosening occurred in one patient at 89 months. This was associated with osteolysis around the distal end of the prosthesis, which was revised into a distal femoral replacement.

One patient complained of persistent anterior knee pain three years after operation. Arthroscopy revealed grade III osteoarthritic changes in her patellofemoral joint with normal patellar tracking. She underwent a chondroplasty, but a lateral release was not required.
One patient developed a periprosthetic fracture around 


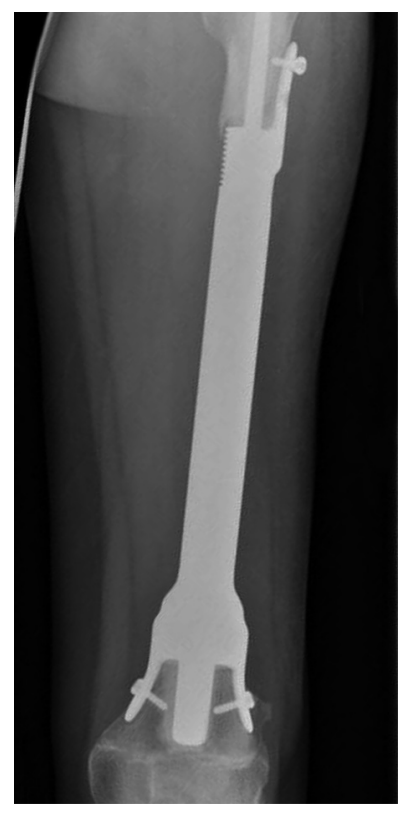

Fig. 6

Post-operative anteroposterior radiograph of patient 22 with a musculoskeletal tumor society score of $87 \%$.

The 16 living patients who retained their diaphyseal endoprosthesis at the time of this review had a mean MSTS score of $87 \%$ (67\% to $93 \%$ ) (Table I). They were all able to perform most activities of daily living comfortably. Only two patients required regular analgesics for control of pain. The remaining two living patients, who had their diaphyseal endoprosthesis revised to a distal femoral replacement, had an MSTS score of $53 \%$ and $67 \%$, respectively.

There was no statistically significant interference of variables such as age $<40(\mathrm{p}=0.212)$, male gender $(\mathrm{p}=0.349)$, administering chemotherapy $(\mathrm{p}=0.499)$ or radiotherapy $(\mathrm{p}=0.071)$ on achieving an MSTS of $87 \%$ or more.

\section{Discussion}

En bloc excision is the mainstay of management for most primary bone tumours. This may be supplemented by adjuvant and/or neoadjuvant treatments, depending on the type of tumour, the grade, the spread and the surgical margins.

Before the development of massive endoprostheses some 30 to 40 years ago, the primary treatment for most bone and soft-tissue sarcomas arising in the limbs was amputation. ${ }^{25}$ However, significant advances in chemo- and radiotherapy, the use of computer technology in endoprosthetic manufacture and the availability of MRI have been paramount in making limb salvage feasible without adversely affecting patient survival. Limb salvage offers considerable advantages in terms of function, appearance and psychological acceptance, ${ }^{26,27}$ and is cost-effective compared to amputation. $^{28}$

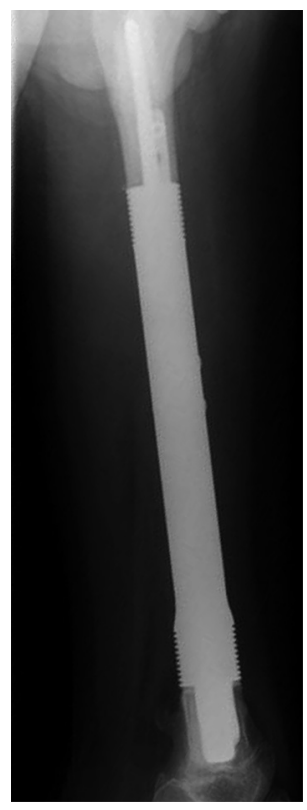

Fig. 7

Post-operative lateral radiograph of the same patient.

It is generally accepted that whereas any limb-salvage procedure should provide equal or greater functional results, the oncological outcome should never be compromised. The ultimate goal must always be to achieve adequate excision of the tumour. Many authors have shown that although limb salvage is associated with a higher rate of local recurrence, there is no compromise in overall patient survival. ${ }^{29,30}$

The options for reconstruction of defects in the femoral diaphysis following resection of the tumour are shown in Table II.

Biological reconstruction is believed to be more timeconsuming than endoprosthetic replacement, with a prolonged period of immobilisation after surgery and a significant risk of nonunion and/or fracture. ${ }^{3-17}$

Many authors have shown that vascularised and nonvascularised autogenous fibular grafts are associated with significant morbidity at the donor site, and are not appropriate for larger defects, which are especially common in the femur. ${ }^{3,16,31}$ Although bony union usually occurs, hypertrophy of the graft sufficient to allow full weightbearing can take many years. A study on reconstruction of femoral defects with autografts has shown an average time to full weight-bearing of about 19 months, with a linear relationship between the length of the segment replaced and the incidence of complications. ${ }^{32}$

The rates of nonunion after massive allograft reconstruction range between $18 \%$ and $64 \%^{10-15}$ and fracture of the graft between $15 \%$ and $51 \% .^{12-15}$ It has been suggested that the rate of nonunion is even higher in patients receiving 
Table II. Comparison of the different methods for reconstruction of diaphyseal defects following segmental resection of a tumour ${ }^{3-23}$

\begin{tabular}{|c|c|c|c|}
\hline Method of reconstruction & Indications/technique & Post-operative care & Failure of reconstruction \\
\hline \multirow[t]{4}{*}{ Autogenous fibular graft } & Can be single or double barrelled & $\begin{array}{l}\text { May require a lengthy period of non- } \\
\text { weight-bearing to allow for union/graft } \\
\text { hypertrophy }\end{array}$ & Fracture: $30 \%$ to $50 \%$ \\
\hline & $\begin{array}{l}\text { Double barrelled required for } \\
\text { femur/pelvis }\end{array}$ & $\begin{array}{l}\text { Average time to full weight-bearing } 28 \text { weeks } \\
\text { (13 to } 45 \text { weeks) }\end{array}$ & Nonunion: $15 \%$ to $25 \%$ \\
\hline & $\begin{array}{l}\text { Can be used with allograft/ } \\
\text { osteosynthesis } \\
\text { bridging }\end{array}$ & & Infection: $10 \%$ to $15 \%$ \\
\hline & & & $\begin{array}{l}\text { May be associated with significant } \\
\text { donor site morbidity }\end{array}$ \\
\hline \multirow[t]{4}{*}{ Massive structural allografts } & Suitable for larger defects (femur) & $\begin{array}{l}\text { May require a lengthy period of non-weight- } \\
\text { bearing to allow for union/incorporation }\end{array}$ & Fracture: $15 \%$ to $50 \%$ \\
\hline & & & Nonunion: $18 \%$ to $64 \%$ \\
\hline & & & Infection: $18 \%$ to $80 \%$ \\
\hline & & & $\begin{array}{l}\text { Loss of strength up to } 50 \% \text { at ten } \\
\text { years }\end{array}$ \\
\hline \multirow[t]{4}{*}{$\begin{array}{l}\text { Extracorporeally irradiated } \\
\text { autogenous bone }\end{array}$} & Suitable for larger defects (femur) & $\begin{array}{l}\text { Irradiated bone is brittle and takes a long time } \\
\text { to revascularise and incorporate into } \\
\text { surrounding bone }\end{array}$ & Fracture: $10 \%$ to $17 \%$ \\
\hline & & $\begin{array}{l}\text { May require a lengthy period of } \\
\text { non-weight-bearing to allow for union/ } \\
\text { incorporation }\end{array}$ & Nonunion: $4 \%$ to $32 \%$ \\
\hline & & & Infection: $0 \%$ to $29 \%$ \\
\hline & & & Bone resorption: $8 \%$ \\
\hline \multirow[t]{3}{*}{$\begin{array}{l}\text { Distraction osteogenesis } \\
\text { (segmental bone transport) }\end{array}$} & $\begin{array}{l}\text { Authors advise against use in } \\
\text { defects larger than } 15 \mathrm{~cm}\end{array}$ & $\begin{array}{l}\text { Gradual distraction starts at } 1 \text { to } 2 \text { weeks } \\
\text { post-operatively at a rate of } 1 \mathrm{~mm} \text { per day }\end{array}$ & Fracture: $15 \%$ \\
\hline & $\begin{array}{l}\text { May not be appropriate for } \\
\text { significant femoral defects }\end{array}$ & Early weight-bearing allowed & Deep infection: $5 \%$ \\
\hline & & & Skin complications: $15 \%$ \\
\hline \multirow[t]{4}{*}{ Endoprosthetic reconstruction } & Suitable for larger defects & Post-operative full weight-bearing permitted & Deep infection: $2 \%$ to $20 \%$ \\
\hline & Custom-made megaprostheses & $\begin{array}{l}\text { Patients can resume near normal function } \\
\text { relatively early }\end{array}$ & Aseptic loosening: $0 \%$ to $35 \%$ \\
\hline & $\begin{array}{l}\text { Fixation with cement and/or } \\
\text { extra-cortical plates }\end{array}$ & & Fracture of prosthesis: $5 \%$ to $15 \%$ \\
\hline & & & Revision rate: $20 \%$ to $35 \%$ \\
\hline
\end{tabular}

adjuvant chemotherapy. ${ }^{33}$ Another study has shown a 50\% loss in strength of the allograft bone after ten years. ${ }^{34}$ Loss of strength was correlated with an increase in the prevalence of microfracture and a reduction in bone mineral density within the cortex of the retrieved allograft. Transmission of disease and infection remains a major concern when using allografts, with rates ranging between $18.5 \%$ and $30 \% .{ }^{14,35,36}$

Extracorporeally irradiated bone, albeit useful to reconstruct a large defect, takes a long time to revascularise and incorporate into surrounding bone. ${ }^{8,9}$ Although the rates of nonunion and fracture are similar to those of allograft bone, the overall rate of complication is up to $52 \% .^{6-9,37}$

Tsuchiya et al $^{18,19}$ were the first to introduce limbsalvage surgery using distraction osteogenesis with conventional bone transport and application of an external fixator. In their studies, patients were allowed to bear weight early, and gradual distraction started between one and two weeks after operation at a rate of $1 \mathrm{~mm}$ per day. Although the reported results were good, the authors advised against using this method for segmental defects exceeding $15 \mathrm{~cm}$ in length, making the technique inappropriate for larger femoral tumours.

Endoprosthetic reconstruction of the femoral diaphysis, although scarcely reported in the literature, generally results in a reasonable functional outcome, allowing patients to bear weight and resume near normal function early. ${ }^{20-22}$ The complications encountered include infection, aseptic loosening, mechanical failure, fracture either of the prosthesis or of adjacent bone, local recurrence and metastatic spread.

Infection remains a major problem and appears to be related to the difficulty of achieving adequate soft-tissue cover for the endoprosthesis and the use of adjuvant immunosuppressive chemo- and radiotherapy. ${ }^{38}$ In our series, only one patient developed deep infection after 12 months with bone loss distally. This required a twostage revision to a distal femoral replacement. Reported rates of infection in other series of endoprosthetic reconstruction range from $2 \%$ to $19.5 \% .39,40$ 
Aseptic loosening of massive tumour endoprostheses is another common complication, with rates ranging between $0 \%$ and $35 \% .{ }^{39-41}$ We had only one case, which occurred at 89 months and required a revision procedure. The recent use of hydroxyapatite collars at the prosthesis-bone junction is believed to reduce the incidence of aseptic loosening by forming a bony bridge sealing the implant-bone interface from wear debris. ${ }^{23}$

We encountered two prosthetic fractures and one periprosthetic fracture, all three were treated by revision procedures. This compares favourably with the rates of fracture reported in biological reconstruction of $15 \%$ to $51 \%$.

Our cumulative patient survival was $77 \%$ at ten years. The mean MSTS score for the patients retaining their diaphyseal endoprosthesis was $87 \%$ (67\% to $93 \%)$. These are good results at nearly ten years following surgery, and compare favourably with three similar published studies. ${ }^{20-22}$ The two patients who had a revision to a distal femoral replacement achieved MSTS scores of $53 \%$ and $67 \%$, respectively. These lower functional scores may be explained by prosthetic replacement of the native knee joint in both cases. This highlights the functional benefits of segmental resection of diaphyseal tumours, as it allows preservation of both the hip and the knee joints.

There may be some limitations to this study, including the possibility of confounding effects due to the wide age range, the relatively low number of patients and the variable duration of follow-up. We conclude that it is always imperative to adhere to the general principles of limb salvage in orthopaedic oncology. Survival should not be compromised by inadequate excision of the tumour, the surgery should ideally allow for immediate weight-bearing and return to function, and the prosthesis used must demonstrate good long-term survival with a low rate of failure. Our results show custom-made femoral diaphyseal endoprosthetic replacement to be a viable and versatile option in appropriate patients. It provides excellent pain relief with a good long-term functional outcome. The complication and revision rates are acceptable when compared with other available methods of treatment.

The authors would like to thank Dr P. Unwin, General Manager of Stanmore Implants Worldwide Ltd (SIW), for his expertise in preparing this article. We also acknowledge the contribution of Mr T. Morris, from the Medical Research Council (MRC) Clinical Trials Unit, Euston, for his help with the statistical analysis.

No benefits in any form have been received or will be received from a commercial party related directly or indirectly to the subject of this article.

\section{References}

1. Clain A. Secondary malignant disease of bone. Br J Cancer 1965;19:15-29.

2. Dorfman HD, Czerniak B. Bone cancers. Cancer 1995;75(1 Suppl):203-10.

3. Chang DW, Weber KL. Use of a vascularized fibula bone flap and intercalary allograft for diaphyseal reconstruction after resection of primary extremity bone sarcomas. Plast Reconstr Surg 2005;116:1918-25.

4. Chen CM, Disa JJ, Lee HY, et al. Reconstruction of extremity long bone defects after sarcoma resection with vascularized fibula flaps: a 10-year review. Plast Reconstr Surg 2007;119:915-24.

5. Zaretski A, Amir A, Meller I, et al. Free fibula long bone reconstruction in orthopedic oncology: a surgical algorithm for reconstructive options. Plast Reconstr Surg 2004;113:1989-2000.
6. Krieg AH, Davidson AW, Stalley PD. Intercalary femoral reconstruction with extracorporeal irradiated autogenous bone graft in limb-salvage surgery. J Bone Joint Surg [Br] 2007;89-B:366-71.

7. Araki N, Myoui A, Kuratsu S, et al. Intraoperative extracorporeal autogenous irradiated bone grafts in tumor surgery. Clin Orthop 1999;368:196-206.

8. Chen TH, Chen WM, Huang CK. Reconstruction after intercalary resection of malignant bone tumours: comparison between segmental allograft and extracorporeally-irradiated autograft. J Bone Joint Surg [Br] 2005;87-B:704-9.

9. Amitani A, Yamazaki T, Sonoda J, et al. Preservation of the knee joint in limb salvage of osteosarcoma in the proximal tibia: a case report. Int Orthop 1988;22:330-4.

10. Makley JT. The use of allografts to reconstruct intercalary defects of long bones. Clin Orthop 1985;197:58-75.

11. Brien EW, Terek RM, Healey JH, Lane JM. Allograft reconstruction after proximal tibial resection for bone tumors: an analysis of function and outcome comparing allograft and prosthetic reconstructions. Clin Orthop 1994;303:116-27.

12. Alman BA, De Bari A, Krajbich Jl. Massive allografts in the treatment of osteosarcoma and Ewing sarcoma in children and adolescents. J Bone Joint Surg [Am] 1995;77-A:54-64.

13. Mankin HJ, Gebhardt MC, Jennings LC, Springfield DS, Tomford WW. Longterm results of allograft replacement in the management of bone tumors. Clin Orthop 1996;324:86-97.

14. Donati D, Di Liddo $\mathbf{M}$, Zavatta $\mathbf{M}$, et al. Massive bone allograft reconstruction in high-grade osteosarcoma. Clin Orthop 2000;377:186-94.

15. Musculo DL, Ayerza MA, Aponte-Tinao L, Ranalletta M, Abalo E. Intercalary femur and tibia segmental allografts provide an acceptable alternative in reconstrucing tumor resections. Clin Orthop 2004;426:97-102.

16. Ogilvie CM, Crawford EA, Hosalkar HS, King JJ, Lackman RD. Long-term results for limb salvage with osteoarticular allograft reconstruction. Clin Orthop 2009;467:2685-90

17. Capanna R, Campanacci DA, Belot $\mathbf{N}$, et al. A new reconstructive technique for intercalary defects of long bones: the associations of massive allograft with vascularized fibular autograft: long-term results and comparison with alternative techniques. Orthop Clin North Am 2007;38:51-60.

18. Tsuchiya H, Tomita K, Minematsu K, et al. Limb salvage using distraction osteogenesis: a classification of the technique. J Bone Joint Surg [Br] 1997;79-B:403-11.

19. Tsuchiya H, Wan SL, Sakayama K, et al. Reconstruction using an autograft containing tumour treated by liquid nitrogen. J Bone Joint Surg [Br] 2005;87-B:218-25.

20. Abudu A, Carter SR, Grimer RJ. The outcome and functional results of diaphyseal endoprostheses after tumour excision. J Bone Joint Surg [Br] 1996;78-B:652-7.

21. Aldlyami E, Abudu A, Grimer RJ, Carter SR, Tillman RM. Endoprosthetic replacement of diaphyseal bone defects: Iong-term results. Int Orthop 2005;29:25-9.

22. AhImann ER, Menendez LR. Intercalary endoprosthetic reconstruction for diaphyseal bone tumours. J Bone Joint Surg [Br] 2006;88-B:1487-91.

23. Blunn GW, Briggs TWR, Cannon SR, et al. Cementless fixation for primary segmental bone tumour endoprostheses. Clin Orthop 2000;372:223-30.

24. Enneking WF, Spanier SS, Goodman MA. A system for the surgical staging of musculoskeletal sarcoma. Clin Orthop 1980;153:106-20.

25. Burrows HJ, Wilson JN, Scales $\mathbf{J T}$. Excision of tumours of humerus and femur, with restoration by internal prostheses. J Bone Joint Surg [Br] 1975;57-B:148-59.

26. Aksnes LH, Bauer HCF, Jebsen NL, et al. Limb-sparing surgery preserves more function than amputation: a Scandinavian sarcoma group study of 118 patients. $J$ Bone Joint Surg Br] 2008;90-B:786-94.

27. Refaat Y, Gunnoe J, Hornicek FJ, Mankin HJ. Comparison of quality of life after amputation or limb salvage. Clin Orthop 2002;397:298-305.

28. Grimer RJ, Carter SR, Pynsent PB. The cost effectiveness of limb salvage surgery for bone tumours. J Bone Joint Surg [Br] 1997;79-B:558-61.

29. Simon MA, Aschliman MA, Thomas N, Mankin HJ. Limb salvage treatment versus amputation for osteosarcoma of the distal end of the femur. J Bone Joint Surg [Am] 1986;68-A:1331-7.

30. Rougraff BT, Simon MA, Kneisel JS, Greenberg DB, Mankin HJ. Limb salvage compared with amputation for osteosarcoma of the distal end of the femur: a longterm oncological, functional, and quality-of-life-study. J Bone Joint Surg [Am] 1994;76-A:649-56.

31. Rose PS, Shin AY, Bishop AT, Moran SL, Sim FH. Vascularized free fibula transfer for oncologic reconstruction of the humerus. Clin Orthop 2005;438:80-4.

32. Han CS, Wood MB, Bishop AT, Cooney WP 3rd. Vascularized bone transfer. J Bone Joint Surg [Am] 1992;74-A:1441-9.

33. Hornicek FJ, Gebhardt MC, Tomford WW, et al. Factors affecting nonunion of the allograft host junction. Clin Orthop 2001;382:87-98. 
34. Fox EJ, Hau MA, Gebhardt MC, et al. Long-term followup of proximal femoral allografts. Clin Orthop 2002;397:106-13.

35. Gebhardt MC, Flugstad DI, Springfield DS, Mankin HJ. The use of bone allografts for limb salvage in high-grade extremity osteosarcoma. Clin Orthop 1991;270:181-96.

36. Wheeler DL, Enneking WF. Allograft bone decreases in strength in vivo over time. Clin Orthop 2005;35:36-42.

37. Fuchs B, Ossendorf C, Leerapun T, Sim FH. Intercalary segmental reconstruction after bone tumor resection. Eur J Surg Oncol 2008;34:1271-6.
38. Jeys LM, Luscombe JS, Grimer RJ, et al. The risks and benefits of radiotherapy with massive endoprosthetic replacement. J Bone Joint Surg [Br] 2007;89-B:1352-5.

39. Guo W, Ji T, Yang R, Tang $\mathbf{X}$, Yang Y. Endoprosthetic replacement for primary tumours around the knee. J Bone Joint Surg [Br] 2008;90-B:1084-9.

40. Gosheger G, Gebert C, Aherns H, et al. Endoprosthetic reconstruction in 250 patients with sarcoma. Clin Orthop 2006;450:164-71.

41. Sewell MD, Spiegelberg BG, Hanna SA, et al. Total femoral endoprosthetic replacement following excision of bone tumours. J Bone Joint Surg [Br] 2009;91B:1513-20. 